\title{
Multicenter cooperative prospective- retrospective observational program for diagnostics and treatment of Hodgkin disease in the North-Western District of Russian Federation (RNWOHG-HD1 Protocol, the full-text version in Russian)
}

\section{Многоцентровая кооперативная проспективно- ретроспективная наблюдательная программа} по оценке методов диагностики и лечения лимфомы Ходжкина в Северо-Западном Федеральном округе РФ

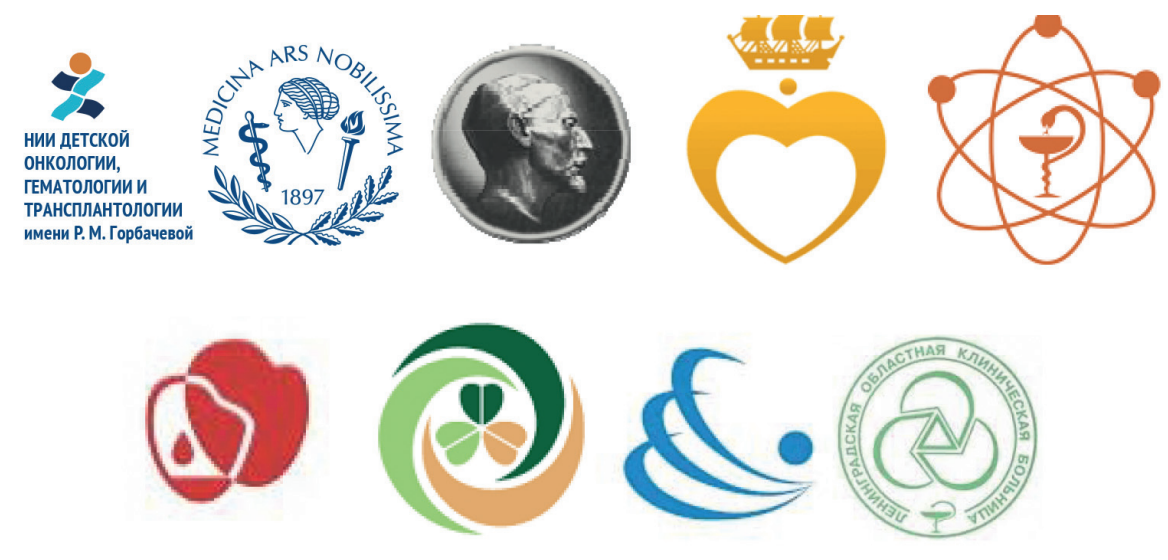

ПРОТОКОЛ № RNWOHG-HDI

ВЕРСИЯ 1.01 ОТ 18.09.2017

ЗАЯВЛЕНИЕ О КОНФИДЕНЦИАЛЬНОСТИ. Этот документ является конфиденциальным и может быть предоставлен для пересмотра только исследователям, потенциальным исследователям, консультантам, персоналу исследования и независимым этическим комитетам или локальным этическим комитетам. Содержимое этого документа не может быть раскрыто третьим лицам без письменного разрешения организации или отдельных лиц, за исключением случаев, когда необходимо получить информированное согласие от потенциальных участников исследования. 


\section{Главные научные кураторы программы и наблюдательный совет:}

«Многоцентровая кооперативная проспективно-ретроспективная наблюдательная программа по оценке эффективности и безопасности лечения лимфомы Ходжкина в Северо-Западном Федеральном округе РФ» инициирована экспертами НИИ детской онкологии, гематологии и трансфузиологии им. Р. М. Горбачевой и ФГБУ «НИИ онкологии им. Н. Н. Петрова» МЗ РФ и будет проводиться под руководством наблюдательного совета.

\section{Главные научные кураторы:}

Афанасьев Борис Владимирович

Директор НИИ детской онкологии, гематологии и трансфузиологии им. Р. М. Горбачевой, заведующий кафедрой гематологии, трансфузиологии и трансплантологии ПСПб ГМУ им. академика И. П. Павлова, д.м.н., профессор

\section{Алексеев Сергей Михайлович}

Заместитель главного врача по гематологии ФГБУ «НИИ онкологии им. Н. Н. Петрова» Минздрава России, руководитель химиотерапевтическое отделение онкологии, гематологии и трансплантации костного мозга, к.м.н.

\section{Моисеев Иван Сергеевич}

Заместитель директора по науке, НИИ детской онкологии, гематологии и трансфузиологии им. Р. М. Горбачевой, заведующий кафедрой гематологии, трансфузиологии и трансплантологии ПСПб ГМУ им. академика И. П. Павлова, к.м.н.

\section{Наблюдательный совет программы:}

\section{Афанасьев Борис Владимирович}

Директор НИИ детской онкологии, гематологии и трансфузиологии им. Р. М. Горбачевой, заведующий кафедрой гематологии, трансфузиологии и трансплантологии СПб ГМУ им. академика И. П. Павлова, д.м.н., профессор

\section{Беляев Алексей Михайлович}

Директор ФГБУ «НИИ онкологии им. Н. Н. Петрова» Минздрава России, главный внештатный онколог Северо-Западного Федерального округа, заведующий кафедрой онкологии Северо-Западного государственного медицинского университета им. И. И. Мечникова, президент Ассоциации онкологов Северо-Запада, д.м.н., профессор

\section{Зарицкий Андрей Юрьевич}

Директор института гематологии ФМИЦ им. В. А. Алмазова, профессор кафедры факультетской терапии Санкт-Петербургского государственного медицинского университета им. акад. И. П. Павлова, д.м.н.

\section{Алексеев Сергей Михайлович}

Заместитель главного врача по гематологии ФГБУ «НИИ онкологии им. Н. Н. Петрова» Минздрава России, руководитель химиотерапевтическое отделение онкологии, гематологии и трансплантации костного мозга, к.м.н.

\section{Ильин Николай Васильевич}

Руководитель радиотерапевтического отделение № 1 Российского Научного Центра Радиологии и Хирургических Технологий, д.м.н., профессор

\section{Михайлова Наталья Борисовна}

Руководитель отдела онкологии и химиотерапии Института детской гематологии и трансплантологии им. Р. М. Горбачевой ПСПбГМУ им. ак. И. П. Павлова, к.м.н

\section{Медведева Надежда Вадимовна}

Руководитель Санкт-Петербургского городского центра онкогематологии на базе ГКБ № 31 заместитель главного врача по медицинской части врач-гематолог высшей квалификационной категории к.м.н.

\section{Манихас Георгий Моисеевич}

Главный врач ГКОД, главный внештатный специалист онколог Санкт-Петербурга, д.м.н., профессор, заслуженный врач РФ

\section{Волошин Сергей Владимирович}

Врач высшей категории, к.м.н., ФГБУ «Российский научно-исследовательский институт гематологии и трансфузиологии Федерального медико-биологического агентства», Санкт-Петербург

\section{Моисеенко Владимир Михайлович}

Руководитель Санкт-Петербургского клинического научно-практического центра специализированных видов медицинской помощи (онкологический), д.м.н., профессор, заслуженный врач РФ

\section{Шнейдер Татьяна Владимировна}

Заведующая онкогематологическим отделением №1 Ленинградской областной клинической больницы, главный внештатный гематолог Ленинградской области 


\section{Список сокращений}

аллоТГСК - аллогенная трансплантация гемопоэтических стволовых клеток

АЛТ - аланинаминотрансфераза

ACT - аспартамаминотрансфераза

аутоТГСК - аутологичная трансплантация гемопоэтических стволовых клеток

БДУ - без дополнительных уточнений

ВБП - выживаемость без прогрессирования

ДО - длительность ответа

ИГХ - иммуногистохимия

КТ - компьютерная томография

лХ - лимфома Ходжкина

OB - общая выживаемость

ПЭТ - позитронной эмиссионной томографии

ПР - полная ремиссия

СОЭ - скорость оседания эритроцитов

ЧО - частичный ответ

eCRF - electronic case report form (электронная индивидуальная регистрационная карта пациента)

SUV - standard uptake value - стандартизированный показатель накопления

Стратификация - процесс или результат разделения выборки на подгруппы (страты) в соответствии с определенными критериями, например, на возрастные, социально-экономические группы

Случайная выборка (Stratified random sample) подразумевает деление популяции на отдельные подгруппы в соответствии с важными характеристиками, например, такими, как возраст или социально-экономический статус, и проведение случайного отбора в каждой из подгрупп. Если из каждой подгруппы (страты) выбирается одинаковая доля, то в выборке будут представлены все страты в таком же соотношении, как в популяции.

\section{СОДЕРЖАНИЕ ПРОТОКОЛА}

1. Главные научные кураторы программы и наблюдательный совет

2. Список сокращений 84

3. Краткое содержание протокола программы 85

4. Актуальность программы 86

5. Задачи программы 86

6. Цель программы 87

7. Первичные конечные точки 87

8. Вторичные конечные точки 87

9. Дизайн программы 87

10. Популяция пациентов, критерии включения и исключения 87

11. Применяемая терапия в рутинной клинической практике в Российской Федерации

12. Обоснование проспективной части наблюдательной программы RNWOHG-HDI

13. Лечение в проспективной группе пациентов наблюдательной программы

14. Методология сбора данных

15. Размер выборки

16. План статистического анализа 92

17. Этические аспекты 93

18. Конфиденциальность персональных данных 93

19. Мониторинг 93

20. Ожидаемые результаты 93

21. Блоки данных, обязательные для регистрации в $\mathrm{e}-\mathrm{CRF}$

22. Приложение 1. Краткое описание схемы лечения в рамках ретроспективной ветки наблюдательной программы RNWOHG-HDI

23. Приложение 2. Схемы химиотерапии и критерии изменения сроков введения и доз препаратов

24. Список литературы 


\section{3. КРАТКОЕ СОДЕРЖАНИЕ ПРОТОКОЛА ПРОГРАММЫ}

\section{Название программы}

Многоцентровая кооперативная проспективно-ретроспективная наблюдательная программа по оценке методов диагностики и лечения лимфомы Ходжкина в Северо-Западном Федеральном округе РФ.

\section{Актуальность}

Заболеваемость лимфомой Ходжкина (ЛХ) в России составляет 2,1 случая на 100000 населения в год (3 164 впервые диагностированных больных). Летальность достигает 0,77 случаев на 100000 населения в год. Заболевание возникает в любом возрасте, но преимущественно в интервале 16-35 лет и в этой возрастной группе преобладают женщины. Отсутствие единых подходов к диагностике и лечению ЛХ в существующей клинической практики негативно отражается на прогнозе пациентов с ЛХ.

\section{Задача программы}

Стратегическая задача программы - стандартизация и улучшение подходов к лечению пациентов с ЛХ в Северо-Западном Федеральном округе Российской Федерации.

\section{Цель программы}

Основная цель - получение данных существующей клинической практики о методах диагностики и лечения ЛХ и сравнение с результатами предлагаемой проспективной схемы лечения на основании оценки выживаемости без прогрессирования и других показателей эффективности и безопасности лечения.

\section{Дизайн программы}

Многоцентровая, кооперативная проспективно-ретроспективная наблюдательная программа с элементом проспективного протокола лечения. Исследование не предусматривает вмешательство в обычный лечебный процесс. Для достижения целей исследования будут анализироваться медицинские карты пациентов.

\section{Длительность программы}

Планируемая длительность программы: на 7 лет с 2018 по 2024 годы. В программу планируется включить не менее 12 центров Северо-Западного Федерального округа РФ. Однако количество центров, принимающих участие в программе, не ограничено территориальным признаком. Планируемая дата закрытия базы данных 31 декабря 2024 года, если не будет принято решение о продолжении программы. Программа может быть остановлена в любой момент при отсутствии финансирования в течении указанного периода.

\section{Популяция пациентов}

В рамках программы планируется проанализировать результаты лечения 900 пациентов, в течение 3 лет пла- нируется включение в программу по 300 пациентов в год. Пациенты будут наблюдаться в течение минимум четырех лет с момента включения в программу и будут постоянно наблюдаться во время и после лечения один раз в три месяца.

\section{Критерии включения пациентов в программу}

- Наличие подтвержденного гистологического диагноза классической лимфомы Ходжкина и возможности стадирования в соответствии с классификацией Ann Arbor;

- Возраст не моложе 16 лет на момент начала лечения;

- Начало лечения лимфомы Ходжкина не ранее 1.01.2017;

- Наличие подписанного информированного согласия на обработку персональных и медицинских данных.

\section{Критерии исключения пациентов из программы}

- Нодулярная лимфома Ходжкина с лимфоцитарным преобладанием.

- Любые серьезные соматические и психические заболевания, которые могут, по мнению исследователя, потенциально помешать завершению лечения.

- Любые серьезные соматические и психические заболевания, не позволяющие пациенту подписать информированное согласие.

- Другое диагностированное злокачественное новообразование с наличием любых признаков активной или остаточной опухоли.

- Любое из следующих сердечно-сосудистых заболеваний или состояний в течение 6 месяцев до начала лечения лимфомы Ходжкина:

- фракция выброса левого желудочка < 50\%;

- инфаркт миокарда в течение 6 месяцев до включения в протокол;

- сердечная недостаточность класса III или IV по классификации Нью-Йоркской кардиологической ассоциации (NYHA);

- признаки текущих неконтролируемых сердечно-сосудистых состояний, включая сердечные аритмии, застойную сердечную недостаточность (ЗСН), стенокардию III-IV функционального класса или электрокардиографические признаки острой ишемии или аномалий проводящей системы сердца.

\section{Методология сбора данных}

Ретроспективно-проспективный сбор данных будет осуществляться на постоянной основе с использованием е-CRF. E-CRF разработана на платформе Quinta (Свидетельство о государственной регистрации программы ЭВМ № 2016615129 «Универсальный программный комплекс для сбора, обработки и управления территориально распределенными клинико-эпидемиологическими данными в режиме удаленного доступа "Quinta»", правообладатель ЗАО «Астон Консалтинг»). Для фиксации данных наблюдении пациентов в электронной карте предусмотрена следующая схема из 18 визитов в течении 4 лет с кратностью внесения информации раз в три месяца: Визит 0 - регистрационный визит, 
Визит 0'/15 - мониторинговые визиты, Визит 16 - закрывающий мониторинговый визит. Регистрационный визит происходит при обращении пациента в любой из включенных в программу центров, и состоит из сбора минимального набора информации: дата обращения, социально демографические данные, данные лабораторных анализов (в том числе патоморфорфологический диагноз), диагноз, назначенное лечение. при включении в программу пациентов, ранее лечившихся по поводу ЛХ, в регистрационную карту будут вноситься ретроспективные данные обследования и лечения и проспективные результаты. Каждый последующий мониторинговый визит собирает всю необходимую медицинскую информацию за прошедшие три месяца, в том числе статус пациента (жив или мертв, в ремиссии или с рецидивом и т.д.), что позволит оценить в последующем общую выживаемость, выживаемость без прогрессирования и другие вторичные точки исследования.

\section{Медико-статистический анализ данных}

Исследование носит описательный характер. Все собранные данные и переменные конечных точек будут суммированы с использованием методов описательной статистики и статистического моделирования. Сводные таблицы будут представлены по группам лечения с включением количества случаев $(\mathrm{N})$, средних значений (M), стандартных отклонений (SD), медиан (Me), минимальных (min) и максимальных (max) значений для непрерывных переменных, а также количества и процентной доли в соответствии с категорией для категориальных данных. Будут представлены кривые выживаемости, полученные по методу Каплана-Майера, и 25-й, 50-й (медиана) и 75-й процентили наряду с анализом значимости при 2-стороннем уровне для 95\% ДИ для данных времени до наступления события. Промежуточный медико-статистический отчет по результатам наблюдений планируется готовить ежегодно. На основании ежегодной оценки результатов планируется принятие решения о необходимости внесения изменений в протокол или прекращение программы. Итоговый аналитический отчет планируется подготовить в феврале 2024 года.

\section{0жидаемый результат}

Ожидается улучшение качества оказания медицинской помощи пациентам с лимфомой Ходжкина в Северо-Западном Федеральном округе Российской Федерации, повышение безрецидивной выживаемости, снижение токсичности проводимой терапии и уменьшение долгосрочных эффектов лечения. Также ожидается снижение финансовой нагрузки на территориальные фонды социального страхования за счет уменьшения числа резистентных пациентов, требующих непрерывного длительного лечения и социальной поддержки. Ожидаемые научные результаты исследования: подтверждение возможности исключения этапа лучевой терапии у пациентов низкого риска с ПЭТ(-) статусом, отсутствие компрометации эффективности лечения при деэскалационной тактике при распространенных стадиях, возможность исключения блеомицина и снижения пульмотоксичности на этапах деэскалации терапии.

\section{ПРОТОКОЛ}

\section{Многоцентровая кооперативная проспектив- но-ретроспективная наблюдательная програм- ма по оценке методов диагностики и лечения лимфомы Ходжкина в Северо-Западном Феде- ральном округе РФ.}

\section{4. АКТУАЛЬНОСТЬ ПРОГРАММЫ}

Заболеваемость лимфомой Ходжкина (ЛХ) в России составляет 2,1 случая на 100000 населения в год (3 164 впервые диагностированных больных). Летальность достигает 0,77 случаев на 100000 населения в год. Заболевание возникает в любом возрасте, но преимущественно в интервале 16-35 лет и в этой возрастной группе преобладают женщины.

Применение полихимиотерапии для лечения лимфомы Ходжкина (ЛХ) позволило добиваться излечения у более 90\% пациентов даже при продвинутых стадиях заболевания, но до настоящего времени главной задачей остается достижение максимального числа полных и стойких ремиссий уже на первой линии терапии, а основными проблемами лечения являются снижение токсичности, деэскалация проводимой терапии без потери эффективности, так же рассматривается вопрос о возможности снижения дозы лучевой терапии, своевременном выполнением ауто- или аллогенной трансплантации костного мозга. При обследовании больных важную, практически определяющую роль для установления диагноза и точного стадирования болезни, и, соответственно, определения тактики лечения, играет позитронно-эмиссионная томография (ПЭТ). Однако в Российской Федерации она не является распространенным методом диагностики, так как возможность ее выполнения имеется не во всех регионах. Поэтому в рутинной практике имеется разброс в выборе методов диагностики и тактики лечения. Отсутствие единых подходов к диагностике и лечению ЛХ в существующей клинической практики негативно отражается на прогнозе пациентов с ЛХ.

\section{5. ЗАДАЧИ ПРОГРАММЫ}

Стратегическая задача программы - стандартизация и улучшение подходов к лечению пациентов с ЛХ в Северо-Западном Федеральном округе Российской Федерации.

Подзадачи наблюдательной программы:

- Организация рабочей научной группы по ЛХ;

- Кумуляция данных о пациентах с ЛХ;

- Направление и координация потока пациентов;

- Увеличение доступа пациентов к высокотехнологическому лечению;

- Оценка возможности выполнения стандартизованного проспективного протокола лечения во все центрахучастниках; 
- Исследование значимости позитронно-эмиссионной томографии в лечении ЛХ.

\section{6. ЦЕЛЬ ПРОГРАММЫ}

Основная цель - получение данных существующей клинической практики о методах диагностики и лечения ЛХ и сравнение с результатами предлагаемой проспективной схемы лечения на основании оценки выживаемости без прогрессирования и других показателей эффективности и безопасности лечения.

\section{7. ПЕРВИЧНЫЕ КОНЕЧНЫЕ ТОЧКИ}

Оценить выживаемость пациентов с ЛХ:

- без прогрессирования;

- с прогрессированием;

- общую выживаемость.

\section{8. ВТОРИЧНЫЕ КОНЕЧНЫЕ ТОЧКИ}

1. влияние методов обследования, верификации диагноза, роли ПЭТ и варианта лечения на свободу от неудач лечения;

2. общая выживаемость (OB);

3. частота полных ремиссий (ПР);

4. частота рецидивов и прогрессирования заболевания;

5. частота ПЭТ-негативного статуса после цикла 2 химиотерапии;

6. частота стабилизации или прогрессирования заболевания после цикла 4 химиотерапии по данным КТ;

7. частота потребности во второй линии терапии;

8. частота объективного ответа при использовании разных вариантов второй линии терапии;

9. частота и потребность выполнения аутологичной трансплантации гемопоэтических стволовых клеток (ауто ТКМ);

10. частота рецидивов и выживаемость без прогрессирования после второй линии терапии с ауто ТКМ;

11. выживаемость без прогрессирования у пациентов при назначении поддержки брентуксимабом после ауто TKM;

12. частота объективного ответа при применении 3-ей линии терапии с применением брентуксимаба;

13. частота рецидивов и выживаемость без прогрессирования после третьей линии терапии с или без алло TKM;

14. частота токсических осложнений на основании использования критериев СТСАЕ ver 4.03;

15. частота инфекционных осложнений (пневмония, сепсис, инфекция мягких тканей, инвазивный аспергиллез, инвазивный кандидоз, вирусные оппортунистические инфекции);

16. оценка использование ресурсов здравоохранения;
17. оценка фертильности на основании частоты удачных беременностей.

\section{9. ДИЗАЙН ПРОГРАММЫ}

Многоцентровая, кооперативная проспективно-ретроспективная наблюдательная программа с элементом проспективного протокола лечения.

Исследование не предусматривает вмешательство в обычный лечебный процесс. Для достижения целей исследования будут анализироваться медицинские карты пациентов.

Планируемая длительность программы: на 7 лет с 2018 по 2024 годы.

В программу планируется включить не менее 12 центров Северо-Западного Федерального округа РФ. Однако количество центров, принимающих участие в программе, не ограничено территориальным признаком.

В рамках программы планируется проанализировать результаты лечения 900 пациентов, в течение 3 лет планируется включение в программу по 300 пациентов в год. Пациенты будут наблюдаться в течение минимум четырех лет с момента включения в программу и будут постоянно наблюдаться во время и после лечения один раз в три месяца.

Планируемая дата закрытия базы данных 31 декабря 2024 года, если не будет принято решение о продолжении программы. Программа может быть остановлена в любой момент при отсутствии финансирования в течении указанного периода.

Промежуточный медико-статистический отчет по результатам наблюдений планируется готовить ежегодно. На основании ежегодной оценки результатов планируется принятие решения о необходимости внесения изменений в протокол или прекращение программы. Итоговый аналитический отчет планируется подготовить в феврале 2024 года. По НЯ отчеты будут готовиться ежеквартально.

\section{0. ПОПУЛЯЦИЯ ПАЦИЕНТОВ, КРИТЕРИИ ВКЛЮЧЕНИЯ И ИСКЛЮЧЕНИЯ}

Взрослые пациенты мужского или женского пола в возрасте от 18 лет и старше с ЛХ (C90) I-IV стадий заболевания с установленным диагнозом классической лимфомы Ходжкина, получающие или получавшие лечение в условиях существующей медицинской практики независимо от линии проведенной терапии.

Кандидаты на участие в программе будут отбираться случайным образом, используя методы, исключающие смещение выборки в сторону преобладания каких-либо 
экономических, социальных, национальных или других групп населения.

Вся персональная информация об участниках исследования будет храниться с соблюдением законов РФ об охране персональных данных.

\section{Критерии включения пациентов в наблюдательную программу:}

- Наличие подтвержденного гистологического диагноза классической лимфомы Ходжкина и возможности стадирования в соответствии с классификацией Ann Arbor;

- Возраст не моложе 16 лет на момент начала лечения;

• Начало лечения лимфомы Ходжкина не ранее 1.01.2017;

- Наличие подписанного информированного согласия на обработку персональных и медицинских данных.

\section{Критерии исключения пациентов из наблюдательной программы:}

- Нодулярная лимфома Ходжкина с лимфоцитарным преобладанием;

- Любые серьезные соматические и психические заболевания, которые могут, по мнению исследователя, потенциально помешать завершению лечения;

- Любые серьезные соматические и психические заболевания, не позволяющие пациенту подписать информированное согласие;

- Другое диагностированное злокачественное новообразование с наличием любых признаков активной или остаточной опухоли;

- Любое из следующих сердечно-сосудистых заболеваний или состояний в течение 6 месяцев до начала лечения лимфомы Ходжкина:

- фракция выброса левого желудочка <50\%;

- инфаркт миокарда в течение 6 месяцев до включения в протокол;

- сердечная недостаточность класса III или IV по классификации Нью-Йоркской кардиологической ассоциации (NYHA);

- признаки текущих неконтролируемых сердечно-сосудистых состояний, включая сердечные аритмии, застойную сердечную недостаточность $(3 \mathrm{CH})$, стенокардию III-IV функционального класса или электрокардиографические признаки острой ишемии или аномалий проводящей системы сердца.

\section{Критерии включения пациентов в проспектив- ный протокол лечения RNWOHG-HD1 в рамках наблюдательной программы:}

1. Пациенты мужского или женского пола в возрасте 18 лет или старше.

2. Пациенты с ЛХ, ранее не получавшие лечения по данному показанию, с рецидивом или прогрессией ЛХ после терапии первой линии, с первым рецидивом или прогрессией после аутоТГСК.
3. Пациенты должны иметь гистологически и иммуногистохимически подтвержденный диагноз классической ЛХ согласно действующей классификации Всемирной организации здравоохранения (нодулярный склероз, смешанная насыщенность клетками, лимфоцитарное преобладание, лимфоцитарное истощение, или же классическая лимфома Ходжкина БДУ (без дополнительных уточнений).

4. Общее состояние по шкале ECOG $\leq 3$ баллов.

5. У пациентов должна присутствовать опухоль, поддающаяся двумерному измерению при регистрации рентгенографическим методом (предпочтительно спиральной КТ) в соответствии с пересмотренными критериями оценки ответа для злокачественных лимфом, изложенных в руководстве Международной рабочей группы (Cheson, 2007)23.

6. Пациентки, которые должны:

- находиться в периоде постменопаузы не менее 1 года до визита в рамках скрининга, ИЛИ

- пройти процедуру хирургической стерилизации, ИЛИ

- если они способны к деторождению, дать свое согласие на использование эффективного метода контрацепции в течение периода от подписания формы информированного согласия и вплоть до 6 месяцев после получения последней дозы химиопрепаратов или последней дозы облучения, или

- дать согласие на полное воздержание от половых контактов, если это согласуется с предпочтительным и обычным укладом жизни пациентки. (Периодическое воздержание [например, календарь, установление факта овуляции, измерение температуры, постовуляционные методы] и прерванный половой акт не являются приемлемыми методами контрацепции.)

Пациенты мужского пола, даже после хирургической стерилизации (т. е. после вазэктомии), которые должны: - дать согласие на использование эффективного барьерного метода контрацепции в течение всего периода лечения в рамках исследования, а также в течение 6 месяцев после химиопрепаратов или последней дозы облучения, ИЛИ

- дать согласие на полное воздержание от половых контактов, если это согласуется с предпочтительным и обычным укладом жизни пациента. (Периодическое воздержание [например, календарь, установление факта овуляции, измерение температуры, постовуляционные методы для партнерш мужчин-участников исследования] и прерванный половой акт не являются приемлемыми методами контрацепции.)

7. Добровольно подписанное согласие должно быть получено до проведения любых связанных с исследованием процедур, не являющихся частью стандартного медицинского лечения, с пониманием того, что согласие может быть отозвано пациентом в любое время без ущерба для предоставляемой в будущем медицинской помощи. 
8. Клинические лабораторные показатели, указанные ниже, полученные в течение 7 дней до начала лечения:

- абсолютное число нейтрофилов $\geq 1500$ /мкл, за исключением известного поражения костного мозга при лХ;

- абсолютное число тромбоцитов $\geq 25$ 000/мкл, за исключением известного поражения костного мозга при лХ;

- общий билирубин должен составлять $\leq 1,5 \mathrm{x}$ от верхней границы нормы (ВГН), за исключением случаев, когда известно, что повышение уровня связано с синдромом Жильбера;

- уровни АЛТ и АСТ должны составлять $\leq 3 \mathrm{x}$ от верхнего предела диапазона нормальных значений; уровни АЛТ и АСТ могут быть до 5 раз выше ВГН, если их повышение может быть обоснованно приписано поражению печени при ЛХ;

- уровень креатинина в сыворотке должен составлять $\leq 200$ мкмоль/л и/или расчетный клиренс креатинина должен составлять $\geq 10$ мл/минуту.

\section{Критерии исключения пациентов из проспек- тивного протокола лечения RNWOHG-HDI в рамках наблюдательной программы:}

1. Лимфома Ходжкина нодулярного типа с лимфоцитарным преобладанием.

2. Пациентки, выделяющие молоко и кормящие грудью, или имеющие положительный результат анализа сыворотки на беременность в рамках периода скрининга или положительный результат анализа на беременность в день 1 перед началом лечения.

3. Любые серьезные соматические и психические заболевания, которые могут, по мнению исследователя, потенциально помешать завершению лечения согласно протоколу.

4. Любые серьезные соматические и психические заболевания, не позволяющие пациенту подписать информированное согласие.

5. Другое диагностированное злокачественное новообразование с наличием любых признаков активной или остаточной опухоли.

6. Любое из следующих сердечно-сосудистых заболеваний или состояний в течение 6 месяцев до начала лечения:

- фракция выброса левого желудочка <50\%;

- инфаркт миокарда в течение 6 месяцев до включения в протокол;

- сердечная недостаточность класса III или IV по классификации Нью-Йоркской кардиологической ассоциации (NYHA);

- признаки текущих неконтролируемых сердечно-сосудистых состояний, включая сердечные аритмии, застойную сердечную недостаточность (3СН), стенокардию III-IV функционального класса или электрокардиографические признаки острой ишемии или аномалий проводящей системы сердца.

\section{1. ПРИМЕНЯЕМАЯ ТЕРАПИЯ В РУТИННОЙ КЛИНИЧЕСКОЙ ПРАКТИКЕ В РОССИЙСКОЙ ФЕДЕРАЦИИ}

В 2014 году были разработаны клинические рекомендации по обследованию и лечению лимфопролиферативных заболеваний, в том числе лимфомы Ходжкина24.

В соответствии с ними стандартом лечения ЛХ для ранних стадий заболевания с благоприятным прогнозом являются 2-4 цикла ПХТ по схеме ABVD с последующей лучевой терапией на зоны исходного поражения в стандартном режиме. Предпочтение отдается 4 циклам ABVD, за исключением тех, кто после тщательно проведенного современного обследования имеет на более 2 зон поражения, отсутствует экстранодальное поражение, массивные конгломераты и ускоренное СОЭ. Вопрос о отмене ЛТ у некоторых больных остается открытым, т.к. до настоящего времени отсутствуют данные клинических исследований, доказывающие эту возможность.

Для ранних стадий с неблагоприятным прогнозом стандартным лечением являются 4-6 циклов ПХТ по схеме ABVD в сочетании с ЛТ СОД 30Гр. на зоны исходного поражения. В группе соматически сохранных больных моложе 50 лет существует возможность применения более интенсивного лечения, которое включает 2 цикла BEACOРР-эскалированный +2 цикла ABVD с последующей ЛТ СОД 30Гр. На зоны исходного поражения. При применении этой программы лечения отмечено увеличение 3-летней выживаемости, свободной от неудач лечения. В тоже время данные о поздней токсичности отсутствуют, поэтому эта программа должна обсуждаться с больными.

Стандартом лечения распространенных стадий является XТ в сочетании с ЛТ на зоны больших опухолевых массивов, оставшихся после ХТ. Больным в возрасте до 60 лет без симптомов интоксикации и с МПИ 0-2 может быть рекомендовано лечение 6 циклами ABVD при достижении полной ремиссии после 4-х циклов или 8 циклов ABVD при достижении частичной ремиссии после 4-х циклов. В этой ситуации возможно проведение только 2 циклов (а не 4-х) -всего 6 циклов и в последующем ЛТ СОД 30Гр. а остаточные опухолевые массы размером более $2,5 \mathrm{~cm}$.

Больным в возрасте до 50 лет с МПИ 3-7 предпочтительнее лечение 6-8 циклами ВЕАСОРР-14 с последующим облучением резидуальных опухолевых масс размером более 2,5 см СОД 30Гр. Подобная терапия приводит к улучшению выживаемости, свободной от неудач лечения, и общей выживаемости. Однако эта схема характеризуется большой токсичностью и требует дополнительного лечения. 
В группе соматически сохранных больных в возрасте 50-60 лет без тяжелой сопутствующей патологии с МПИ 3-7 возможно проведение лечения по программе 6-8 циклов ВЕАСОРР-14 с последующим облучением резидуальных опухолевых масс размером более 2.5 см СОД 30Гр.

Терапией выбора для всех больных старше 60 лет остается режим $\mathrm{ABVD}+Л \mathrm{~T}$ на резидуальную опухоль размером более 2.5 см СОД 30Гр. ВЕАСОРР-14 является высокотоксичным режимом для большинства этих больных.

Таким образом, в Российской Федерации большинство центров используют протоколы ABVD, BEACOPP-14 или ВЕАСОРР эскалированный для различных стадий, групп риска и возрастных групп. Во второй линии терапии рекомендуется использование высокодозных схем DHAP, IGEV и др. Тем не менее, есть центры, рассматривающие возможность проведения ВЕАСОРР во второй линии, если в первой был ABVD. Проспективно-ретроспективная часть программы оценит эффективность этих терапевтических подходов.

\section{Лечение и стадирование с применением ПЭТ- стратегии}

Крайне большую роль в современной терапии ЛХ, как уже упоминалось выше, играет ПЭТ-исследование, которое позволяет выделять группы риска, вовремя деэскалировать терапию со снижением токсичности у пациентов с благоприятным прогнозом и эскалировать у пациентов с неблагоприятным течением заболевания.

Было показано, что ключевым моментом в лечении является ПЭТ-ответ после двух курсов химиотерапии. Мониторинг ПЭТ в эти сроки позволяет завершить терапию двумя циклами ABVD при ранних стадиях ${ }^{12}$, при распространенных стадиях выделить группу пациентов, у которых можно уменьшить токсичность за счет исключения блеомицина из $\mathrm{ABVD}^{13}$, и выделить неблагоприятную группу пациентов, которым требуется продолжение интенсивной терапии BЕАСОРР14 или BEACOPPesc ${ }^{14}$

\section{2. ОБОСНОВАНИЕ ПРОСПЕКТИНОЙ ЧАСТИ НАБЛЮДАТЕЛЬНОЙ ПРОГРАММЫ RNWOHG-HDI}

Внедрение полихимиотерапии для лечения лимфомы Ходжкина (ЛХ) в 1970-х годах позволило добиваться излечения у более 70\% пациентов даже при продвинутых стадиях заболевания ${ }^{1}$. С этого периода времени длительное время стандартом лечения оставалась схема ABVD в сочетании с радиотерапией. В ряде стран, таких как США, данная схема остается стандартом². Тем не менее, дальнейшее улучшение результатов лечения ЛХ связано с обширной исследовательской работой German Hodgkin Study Group и внедрением вариантов протокола BEAСОРР. В исследовании HD9 было показано, что при продвинутых стадиях ЛХ использование
BEACOPP escalated (esc) позволяет излечивать до $87 \%$ пациентов, при этом ВЕАСОРР стандартный показывает достоверно худшие результаты лечения ${ }^{3}$. Для ранних стадий нет преимуществ BEACOPP над ABVD, поэтому ABVD остается стандартом ${ }^{4}$. Тем не менее, использование такой агрессивной терапии, как BEACOPPesc приводит к повышению гематологической токсичности, нарушениям фертильности и некоторым увеличением частоты вторичных опухолей ${ }^{3,5,6}$. Поэтому целью дальнейших исследований стало снижение токсичности терапии в группе высокого риска. Одним из подходов уменьшение интервала введения химиопрепаратов при снижении доз. Данный подход показывает сравнимую эффективность схем BEACOPP14 и BEACOPPesc и несколько меньшую токсичность ВЕАСОРР 14, поэтому данные схемы можно считать эквивалентными ${ }^{7}$. Другой подход к снижению токсичности - деэскалация терапии после двух циклов при достижении полной ремиссии. Было показано, что при переходе на BEACOPP ${ }^{8}$ standard и даже $\mathrm{ABVD}^{9}$ без снижения эффективности. Параллельно шли исследования возможности уменьшения дозы лучевой терапии. Было показано, что снижение дозы облучения до 20 Gy при ранних стадиях не приводило к повышению частоты рецидивов ${ }^{10}$, более того достижение ПЭТ (-) статуса при ранних стадиях ЛХ после ABVD, или при продвинутых стадиях после BEACOPP, позволяет радиотерапию не проводить ${ }^{11}$.

Крайне большую роль в современной терапии ЛХ, как уже упоминалось выше, играет ПЭТ-исследование, которое позволяет выделять группы риска, вовремя деэскалировать терапию со снижением токсичности у пациентов с благоприятным прогнозом и эскалировать у пациентов с неблагоприятным течением заболевания. Было показано, что ключевым моментом влечение является ПЭТ-ответ после двух курсов химиотерапии. Мониторинг ПЭТ в эти сроки позволяет завершить терапию двумя циклами ABVD при ранних стадия ${ }^{12}$, при продвинутых стадиях выделить группу пациентов, у которых можно уменьшить токсичность за счет исключения блеомицина из $\mathrm{ABVD}^{13}$, и выделить неблагоприятную группу пациентов, которым требуется продолжение интенсивной терапии BEACOPP14 или BEACOPPesc ${ }^{14}$.

Таким образом, в основу данного протокола лечения ЛХ легка ПЭТ-адаптированная стратегия с разделением на группы риска. Пациента с ранними стадиями ЛХ при достижении ПЭТ(-) ремиссии не получают дальнейшего лечения, пациенты с ПЭТ (+) статусов в зависимости от степени ответа продолжают ABVD или переходят на терапию BEACOPPesc/BEACOPР14 20 Gy. При неблагоприятных факторах прогноза и продвинутых стадиях планируется деэскалационная стратегия с переходом на AVD/ABVD после двух циклов BEACOPPesc/BEACOPP14. В ходе деэскалации планируется рандомизацию с целью подтверждения возможности исключения блеомицина в ходе дальнейшей терапии при ПЭТ(-)-статусе. Пациенты, остающиеся ПЭТ(+) после 2 курсов получают полную интенсивную терапию BEACOPPesc/BEACOPP14 до 6 циклов \pm радиотерапия в дозе 20 Gy в зависимости от ответа. Учитывая многочисленные данные об эквивалентности BEACOPPesc 
и BEACOPР $14^{7,13}$, выбор варианта терапии остается на усмотрение учреждений здравоохранения.

Отдельной веткой протокола является лечение пациентов, инфицированных вирусом иммунодефицита человека (ВИЧ). В этой группе пациентов химиотерапия переносится существенно хуже, использование схем на основе ВЕАСОРР приводит к значительной гематологической токсичности и инфекционным осложнениям ${ }^{15,16}$. Поэтому для данной группы планируется использовать только ABVD в первой линии, с попыткой исключения блеомицина в ходе проведения 3-6 циклов. Как и в основной группе планируется использование ПЭТ после 2-х курсов для сокращения терапии или раннего перехода на 2-ую линию (рис.2).

Данный протокол предусматривает также проведение 2-ой и третьей линии терапии. Выбор варианта второй линии остается на усмотрение учреждений здравоохранения, учитывая сравнимую эффективность схем терапии DHAP, ICE, IGEV, брентуксимаба и бендомустина с брентуксимабом $^{17-19}$. Для пациентов с IPS 4 или первично химиорезистентной опухолью в рамках 2-ой линии рекомендовано проведение терапии брентуксимабом и бендомустином, учитывая, что в этой группе пациентов эффективность химиотерапии во второй линии значительно ниже и обычно не превышает 20\%20. Проведение аутологичной и аллогенной ТГСК будет проводится в центрах Северо-Западного Федерального округа РФ в соответствии с внутренними протоколами. Для пациентов с факторами риска рецидива после аутологичной трансплантации, такими как рецидив ранее 1 года от момента лечения, bulky опухоль, экстрамедуллярные очаги и менее полной ремиссии после 2-ой линии, допустимо проведение поддержки брентуксимабом ${ }^{21,22}$.

\section{3. ЛЕЧЕНИЕ В ПРОСПЕКТИВНОЙ ГРУППЕ НАБЛЮДАТЕЛЬНОЙ ПРОГРАММЫ}

При невозможности выполнения ПЭТ-исследования в процессе лечения, используются схемы лечения на выбор центра, участника наблюдательной программы.

В случае возможности выполнения ПЭТ-исследования (3 раза для терапии 1-ой линии, 2 раза для терапии второй линии, 2 раза для терапии 3-ей линии) в процессе лечения, участники наблюдательной программы заявляют о намерении лечить пациентов в соответствии со стандартизованным риск-адаптированным ПЭТ-направленным протоколом лечения, далее именуемым RNWOHG-HD1. Схема лечения представлена в приложении 1 (рисунок 1). Схемы лечения, критерии переноса начала курсов и критерии редукции доз при почечной и печеночной недостаточности представлены в приложении 2. Требуется отметить, что проспективная часть программы RNWOHG-HD1 не использует незарегистрированные для лечения ЛХ препараты. Все курсы полихимиотерапии, входящие в данную программу, перечислены в национальных рекомендациях 2014 года.
Особенностью протокола является только их последовательная комбинация на основании ПЭТ-направленных эскалационных и деэскалационная стратегий.

Лечение ЛХ у пациентов с ВИЧ планируется по отдельному протоколу. Схема протокола представлена в приложении 1 (рисунок 2). В протоколе для ВИЧ-ассоциированной ЛХ также используются только курсы, перечисленные в национальных рекомендациях 2014 года.

\section{4. МЕТОДОЛОГИЯ СБОРА ДАННЫХ}

Поскольку данный проект представляет собой наблюдательную программу, то обязательное оценивание пациентов или центров не требуется. Тем не менее сбор данных/отчетности будет проводиться на постоянной основе во избежание предвзятости в процессе сбора данных и анализа. Собранные данные будут загружаться всеми исследовательскими центрами в электронную систему с использованием утвержденной электронной индивидуальной регистрационной карты пациента (eCRF) и верифицироваться. Данные, необходимые с точки зрения основных целей исследования, а также демографические данные и клинические характеристики пациентов будут браться из еCRF, заполненных персоналом центров.

E-CRF разработана на платформе Quinta (Свидетельство о государственной регистрации программы ЭВМ № 2016615129 «Универсальный программный комплекс для сбора, обработки и управления территориально распределенными клинико-эпидемиологическими данными в режиме удаленного доступа «Quinta»», правообладатель $3 \mathrm{AO}$ «Астон Консалтинг»). Ее использование происходит через индивидуальный электронный удаленный on-line доступ: индивидуальный логин и пароль. Рекомендованный браузер для работы Microsoft Internet Explorer 10.0 (интернет настройка).

Для фиксации данных наблюдении пациентов в электронной карте предусмотрена следующая схема из 18 визитов в течении 4 лет с кратностью внесения информации раз в три месяца: Визит 0 - регистрационный визит, Визит 0'/ 15 - мониторинговые визиты, Визит 16 - закрывающий мониторинговый визит. Регистрационный визит происходит при обращении пациента в любой из включенных в программу центров, и состоит из сбора минимального набора информации: дата обращения, социально демографические данные, данные лабораторных анализов (в том числе патоморфорфологический диагноз), диагноз, назначенное лечение. При включении в программу пациентов, ранее лечившихся по поводу ЛХ, в регистрационную карту будут вноситься ретроспективные данные обследования и лечения и проспективные результаты. Каждый последующий мониторинговый визит собирает всю необходимую медицинскую информацию за прошедшие три месяца, в том числе статус пациента (жив или мертв, в ремиссии или с рецидивом и т.д.), что позволит оценить в последующем общую выживаемость, выживаемость без прогрессирования и другие вторичные точки исследования. 


\section{5. РАЗМЕР ВЫБОРКИ}

Поскольку программа является наблюдательной и не предлагает доказательства никакой гипотезы, то расчет выборки не производился. Однако в программу планируется достаточное для поставленных задач число пациентов - 900 человек.

\section{6. ПЛАН СТАТИСТИЧЕСКОГО АНАЛИЗА}

Исследование носит описательный характер. Все собранные данные и переменные конечных точек будут суммированы с использованием методов описательной статистики и статистического моделирования. Сводные таблицы будут представлены по группам лечения с включением количества случаев $(\mathrm{N})$, средних значений (M), стандартных отклонений (SD), медиан (Me), минимальных $(\min )$ и максимальных $(\max )$ значений для непрерывных переменных, а также количества и процентной доли в соответствии с категорией для категориальных данных. Будут представлены кривые выживаемости, полученные по методу Каплана-Майера, и 25-й, 50-й (медиана) и 75-й процентили наряду с анализом значимости при 2-стороннем уровне для 95\% ДИ для данных времени до наступления события.

\section{Статистические методы}

Сравнение непараметрических величин между группами будет проводиться тестом Манна-Уитни.

Сравнение числовых переменных между группами будет проводится двусторонним t-тестом. Сравнение показателей выживаемости без прогрессирования (ИБП) и общей выживаемости (OB) между группами лечения будет проводится с использованием log-ранг теста. Многофакторный анализ ВБП и ОВ будет проводиться на основании построения моделей пропорционального риска. Для пациентов, которым проводится аутологичная и аллогенная ТСК трансплантационная летальность и рецидивы будут расцениваться как конкурирующие риски. Статистическая значимость для всех тестов устанавливается на уровне 0.05 .

Расчет фармакоэкономики на одного пациента будет проводиться исходя из следующих параметров: стоимость химиопрепаратов и сопроводительных препаратов, стоимость дополнительных исследований, стоимость логистических и дополнительных расходов, стоимость лечения осложнений в соответствии со стандартами МЗ РФ, расходы на оплату нетрудоспособности, исходя из параметров средней заработной платы по региону и длительности лечения по протоколу.

\section{Статистическая обработка полученных результатов:}

В целом, сводные таблицы будут представлены по группам лечения с включением количества случаев, средних значений, стандартных отклонений, медиан, минимальных и максимальных значений для непрерывных переменных, а также количества и процентной доли в соответствии с категорией для категориальных данных. Будут представлены кривые выживаемости, полученные по методу Каплана-Майера, и 25-й, 50-й (медиана) и 75-й процентили наряду с анализом значимости при 2-стороннем уровне для 95\% ДИ для данных времени до наступления события.

\section{Определение конечных точек исследования:}

Выживаемость без прогрессирования: время от начала лечения в рамках 1-ой, 2-ой или 3-ей линии химиотерапии до смерти, рецидива или прогрессии ЛХ.

Общая выживаемость: время от начала лечения в рамках 1-ой, 2-ой или 3-ей линии химиотерапии до смерти.

Полная ремиссия: ПЭТ- негативный статус (Deauville $\leq 3)$ даже при сохраняющихся резидуальных массах ${ }^{20}$.

Частичный ответ: Регресс $\geq 50 \%$ шести наиболее крупных опухолевых масс при отсутствии появления новых опухолевых очагов и одного или более ПЭТ- позитивного опухолевого очага ${ }^{20}$.

Прогрессия/рецидив: появление новых опухолевых очагов более 1.5 см, или увеличение на 50\% суммы диаметров по крайней мере одного из опухолевых очагов, или увеличение на 50\% в одном измерении ранее существовавшего очага> 1 см, или появление новых ПЭТ- позитивных опухолевых очагов (Deauville $>3)^{20}$.

Пациенты будут исследоваться в течение как минимум четырех лет с момента начала терапии и будут постоянно наблюдаться в течении и после лечения один раз в три месяца до момента, когда ими будет отозвано согласие на участие или до момента смерти, или исчезновения из поля зрения исследователей.

\section{Рандомизация}

В группе пациентов, которые с самого начала лечения курировались с использованием ПЭТ будет проводится рандомизация. Рандомизация будет проводиться на момент достижения полной ПЭТ-негативной ремиссии после двух курсов терапии в группе высокого риска. В ходе рандомизации будет выполняться стратификация риска по IPS на основании U-критерия теста Манна-Уитни.

С учетом рандомизации $60 \%$ всех пациентов, включенных в программу, отношение риска худшего результата (inferiority) на 1, 2 и 3 года рассчитывается из числа 180, 360 и 540 пациентов, с ожидаемой частотой наступления события 15\%, выбранной на основании литературных данных $^{13}$. Сила анализа - 80\%. Исходя из количества пациентов и силы исследования за худший результат (inferiority) принимается отношение рисков (HR) БРВ $11.0,3.5$ и 2.2 для промежуточного анализа на 1,2 и 3 года исследования, соответственно. Результаты промежуточного анализа предоставляются наблюдательному 
совету для решения вопроса о целесообразности продолжения рандомизации. При оценке окончательных показателей 5-летней БРВ худший результат (inferiority) $\mathrm{HR}>1.1$.

\section{7. ЭТИЧЕСКИЕ АСПЕКТЫ}

Данная программа была разработана и будет проводиться в соответствии с этическими принципами Хельсинской декларации, трехсторонним соглашением Международной Конференции по Гармонизации и российским ГОСТом по надлежащей клинической практике.

Пациенты, подходящие по критериям, могут быть включены в программу только после подписания формы информированного согласия, одобренной Независимым или Локальным Этическим Комитетом. Подписанное информированное согласие необходимо получить до применения процессов, описанных в настоящем протоколе. Процесс получения подписанного информированного согласия должен быть отражен в первичной исследовательской документации по каждому пациенту.

Персональные данные пациентов будут использоваться исключительно в целях наблюдательной программы. Любая информация, с помощью которой можно идентифицировать пациентов, не подлежит раскрытию. Идентификация пациентов в базе данных будет осуществляться на сновании присвоенных номеров.

В силу наблюдательного и неинтервенционного характера данного исследования протокол исследования, карта пациента, форма информированного согласия и информация, предоставляемая пациентам, не должны получать одобрения российского Министерства здравоохранения и социального развития, Совета по этике при Министерстве Здравоохранения и этических комитетов в местах проведения исследования.

\section{8. КОНФИДЕНЦИАЛЬНОСТЬ ПЕРСОНАЛЬНЫХ ДАННЫХ}

Конфиденциальность ПД находится под защитой действующего законодательства. ЗАО «Астон Консалтинг» является официально зарегистрированным оператором персональных данных (ссылка на документ), что дает возможность врачу-участнику программы при подписании информированного согласия не кодировать пациентов, вносить их персональные данные (а именно ФИО, дату рождения, возраст) в базу данных для обработки (информированное согласие - приложение 4). После введения ФИО пациента е-CRF генерирует код, под которым пациент будет виден другим участникам программы, не имеющим доступ к полной базе данных.

Персональные данные пациентов, принимающих участие в программе, будут сохраняться в тайне. Идентификация пациентов будет осуществляться при помощи уникальных номеров, присвоенных пациентам е-CRF.

\section{9. МОНИТОРИНГ}

Мониторинг во всех центрах, включающих пациентов в программу будет проводиться 2 раза в год. В случае выявления несоответствия первичной медицинской документации и еCRF, которые не повлияли на выбор схем лечения, eCRF приводится в соответствие с первичной документацией.

\section{0. ОЖИДАЕМЫЕ РЕЗУЛЬТАТЫ}

Ожидается улучшения качества оказания медицинской помощи пациентам с ЛХ в Северо-Западном Федеральном округе Российской Федерации, повышение безрецидивной выживаемости, снижение токсичности проводимой терапии и уменьшение долгосрочных эффектов лечения. Также ожидается снижение финансовой нагрузки на территориальные фонды социального страхования за счет уменьшения числа резистентных пациентов, требующих непрерывного длительного лечения и социальной поддержки. Ожидаемые научные результаты исследования: подтверждение возможности исключения этапа лучевой терапии у пациентов низкого риска с ПЭТ(-) статусом, отсутствие компрометации эффективности лечения при деэскалационной тактике при распространенных стадиях, возможность исключения блеомицина и снижения пульмотоксичности на этапах деэскалации терапии.

\section{1. БЛОКИ ДАННЫХ, ОБЯЗАТЕЛЬ- НЫЕ ДЛЯ РЕГИСТРАЦИИ В Е-CRF:}

Схематичная форма регистрируемых параметров представлена в приложении 5.

Первичная регистрация в электронной системе:

1. Фамилия/Имя/Отчество

2. Пол

3. Дата рождения Возраст (калькулятор)

4. Регион

5. Телефон для связи

6. Социальный статус (работающий, неработающий, учащийся, пенсионер)

7. Дата внесения регистрационной информации

Первичное стадирование:

1. Дата постановки диагноза

2. Длительность заболевания на момент включения пациента в программу

3. Гистологический вариант заболевания

4. Дата биопсии, по которой был поставлен гистологический диагноз

5. Проводилось ли ИГХ диагностика:

6. Если проводилась ИГХ диагностика, необходимо отметить ИГХ Маркеры (нужное отметить) 


\begin{tabular}{|c|c|c|c|}
\hline $\begin{array}{c}\text { ИГХ Маркеры (нужное } \\
\text { отметить) }\end{array}$ & маркер & $\begin{array}{c}\text { Делали (да)|не делали } \\
\text { (нет) }\end{array}$ & $\begin{array}{c}\text { Результат: «+» } \\
\text { положительный, «-» } \\
\text { отрицательный }\end{array}$ \\
\hline 1 & CD 30 & & \\
\hline 2 & CD 15 & & \\
\hline 3 & CD 20 & & \\
\hline 4 & $\mathrm{CD} 3 / \mathrm{CD} 2$ & & \\
\hline 5 & CD 40 & & \\
\hline 6 & CD 45 & & \\
\hline 7 & EBV-LMP-1/EBER (ISH) & & \\
\hline 8 & ALK & & \\
\hline 9 & Fascin & & \\
\hline 10 & IRF4/MUMI & & \\
\hline 11 & PAX5 & & \\
\hline 12 & CD57 & & \\
\hline 13 & CD 75 & & \\
\hline 14 & OCT 2 & & \\
\hline 15 & BOBI & & \\
\hline $\begin{array}{c}\text { количество проведенных } \\
\text { ИГХ реакций }\end{array}$ & калькулятор & & \\
\hline $\begin{array}{c}\text { морфологический диагноз } \\
\text { референсного центра }\end{array}$ & $\begin{array}{c}\text { справочник гистологической } \\
\text { классификации лимфом }\end{array}$ & комментарий & \\
\hline
\end{tabular}

\section{7. Стадия по классификации Ann Arbor}

8. Вовлеченные зоны по данным ПЭТ-КТ

9. Максимальные размеры опухоли для 6 очагов (либо меньше, если вовлечены менее 6)

10. Уровень метаболической активности по Deauville для 6 очагов (либо меньше, если вовлечены менее 6)

11. ВИЧ-статус (в случае положительного - вирусная нагрузка, CD4+ в мкл).

12. $\mathrm{COЭ}$

13. ЛДГ

14. АЛТ

15. ACT

16. Креатинин

17. Билирубин

18. Гемоглобин

19. Альбумин

20. Абсолютное число лейкоцитов

21. Абсолютное число нейтрофилов

22. Абсолютное число лимфоцитов

23. Тромбоциты

24. Вариант терапии первой линии

25. Запланированное число курсов (не для RNWOHGHD1)

26. Дата начала 1-ого цикла химиотерапии

27. Препараты 1ого цикла химиотерапии: длительность и дозы
Рестадирование после двух циклов химиотерапии:

1. Дата начала 2-ого цикла химиотерапии

2. Препараты 2-ого цикла химиотерапии: длительность и дозы

3. Ответ по оценке лечащего врача

4. Максимальный уровень метаболической активности по Deauville

5. Вовлеченные зоны по данным ПЭТ-КТ

6. Максимальные размеры опухоли для 6 очагов (либо меньше, если вовлечены менее 6)

7. Уровень метаболической активности по Deauville для 6 очагов (либо меньше, если вовлечены менее 6)

8. Токсичность, если была, по NCI CTCAE 4.03

9. Инфекционные осложнения, если были

10. Потребность в Г-КСФ

11. Количество переливаний эритроцитов

12. Другая сопроводительная терапия

Рестадирование после четырех циклов химиотерапии (где применимо):

1. Дата начала курсов химиотерапии

2. Препараты химиотерапии

3. Ответ по оценке лечащего врача

4. Максимальный уровень метаболической активности по Deauville

5. Вовлеченные зоны по данным КТ 
6. Максимальные размеры опухоли для 6 очагов (либо меньше, если вовлечены менее 6)

7. Токсичность, если была, по NCI CTCAE 4.03

8. Инфекционные осложнения, если были

9. Потребность в Г-КСФ

10. Количество переливаний эритроцитов

11. Другая сопроводительная терапия

12. Рестадирование после шести циклов химиотерапии (где применимо):

13. Дата начала курсов химиотерапии

14. Ответ по оценке лечащего врача

15. Максимальный уровень метаболической активности по Deauville

16. Вовлеченные зоны по данным ПЭТ-КТ

17. Максимальные размеры опухоли для 6 очагов (либо меньше, если вовлечены менее 3)

18. Уровень метаболической активности по Deauville для 6 очагов (либо меньше, если вовлечены менее 6)

19. Токсичность, если была, по NCI CTCAE 4.03

20. Инфекционные осложнения, если были

21. Потребность в Г-КСФ

22. Количество переливаний эритроцитов

23. Другая сопроводительная терапия

Рестадирование после лучевой терапии (где применимо):

1. Дата начала лучевой терапии

2. Режим лучевой терапии

3. Доза лучевой терапии

4. Ответ по оценке лечащего врача

5. Максимальный уровень метаболической активности по Deauville

6. Вовлеченные зоны по данным КТ

7. Максимальные размеры опухоли для 6 очагов (либо меньше, если вовлечены менее 6)

8. Токсичность, если была, по NCI CTCAE 4.03

Наблюдение каждые 6 месяцев после окончания лечения:

1. Дата контакта

2. Жив/умер/потеряна связь

3. Статус заболевания

4. Остаточные побочные явления, если есть, по NCI CTCAE 4.03

5. Для женщин факт наличия беременности (планировалась - не было, не планировалась - не было, была аборт, в анамнезе - невынашивание, в анмнезе - роды)

Статус на момент рецидива/прогрессии после 1-ой линии (где применимо):

1. Дата фиксации рецидива

2. Длительность от момента первичной диагностики заболевания

3. Стадия по классификации Ann Arbor

4. Вовлеченные зоны по данным ПЭТ-КТ
5. Максимальные размеры опухоли для 6 очагов (либо меньше, если вовлечены менее 3)

6. Уровень метаболической активности по Deauville для 6 очагов (либо меньше, если вовлечены менее 6)

7. $\mathrm{CO}$

8. ЛДГ

9. АЛТ

10. ACT

11. Креатинин

12. Билирубин

13. Гемоглобин

14. Альбумин

15. Абсолютное число лейкоцитов

16. Абсолютное число нейтрофилов

17. Абсолютное число лимфоцитов

18. Тромбоциты

19. Дата начала химиотерапии второй линии

20. Вариант химиотерапии второй линии: DHAP, IGEV, ICE, брентуксимаб, брентуксимаб + бендамустин, BEACOPP, DexaBeam, LABO, другая (вписать)

Статус после 2-ой линии химиотерапии (где применимо):

1. Дата рестадирования

2. Ответ по оценке лечащего врача

3. Максимальный уровень метаболической активности по Deauville

4. Вовлеченные зоны по данным ПЭТ-КТ

5. Максимальные размеры опухоли для 6 зон (либо меньше, если вовлечены менее 6)

6. Уровень метаболической активности по Deauville для 6 зон (либо меньше, если вовлечены менее 3 )

7. Токсичность, если была, по NCI CTCAE 4.03

8. Инфекционные осложнения, если были

9. Потребность в Г-КСФ

10. Количество переливаний эритроцитов

11. Другая сопроводительная терапия

12. Направлен на аутоТКМ: да/нет

13. Причина, если не направлен на аутоТКМ: не кандидат (и причина), неудача сбора стволовых клеток, отзыв согласия

Статус после аутоТКМ (где применимо):

1. Дата ТКМ

2. Дата рестадирования

3. Режим кондиционирования

4. Количество CD34+ в трансплантате

5. Ответ по оценке лечащего врача

6. Максимальный уровень метаболической активности по Deauville

7. Вовлеченные зоны по данным ПЭТ-КТ

8. Максимальные размеры опухоли для 6 зон (либо меньше, если вовлечены менее 6) 
9. Уровень метаболической активности по Deauville для 6 зон (либо меньше, если вовлечены менее 6)

10. Токсичность, если была, по NCI CTCAE 4.03

11. Инфекционные осложнения, если были

12. Поддерживающая терапия брентуксимабом - да/нет

Статус на момент рецидива/прогрессии после 2-ой линии (где применимо):

1. Стадия по классификации Ann Arbor

2. Вовлеченные зоны по данным ПЭТ-КТ

3. Максимальные размеры опухоли для 6 зон (либо меньше, если вовлечены менее 6)

4. Уровень метаболической активности по Deauville для 6 зон (либо меньше, если вовлечены менее 6)

5. $\mathrm{CO}$
6. ЛДГ

7. Гемоглобин

8. Альбумин

9. Абсолютное число лейкоцитов

10. Абсолютное число нейтрофилов

11. Абсолютное число лимфоцитов

12. Тромбоциты

13. Дата начала терапии третьей линии

14. Вариант терапии третьей линии: брентуксимаб или другой

15. Направлен на аллоТКМ да/нет

16. Причины невыполнения аллоТКМ: нет донора/отзыв согласия/другая

\section{2. ПРИЛОЖЕНИЕ 1. Краткое описание схемы лечения ретроспективной ветки наблюдательной программы RHWOHG-HDI}

\section{Рисунок 1. Схема лечения с использованием ПЭТ}

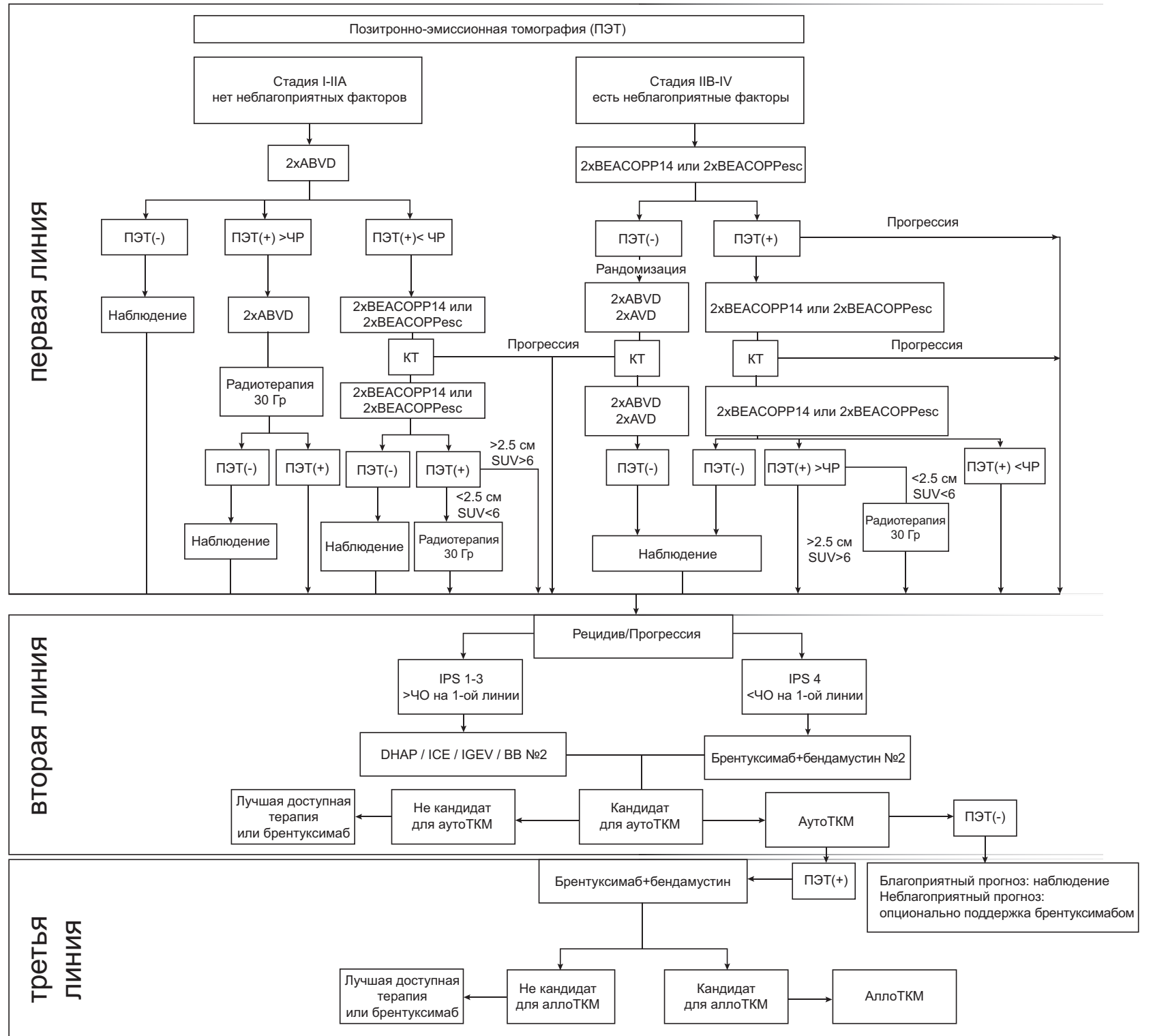


Пациенты ретроспективной ветки наблюдательной программы RHWOHG-HD1, могут быть отнесены к группе интенсивного или неинтенсивного ведения.

Неблагоприятные факторы, требующие включения пациента к интенсивной ветке протокола лечения:

- массивная (bulky) медиастинальная опухоль >10 cм

- экстранодальное поражение, в том числе по контакту

- скорость оседания эритроцитов (СОЭ) >50 мм/ч

- вовлечение трех и более групп лимфоузлов.

\section{Первая линия}

\section{Неинтенсивная ветка протокола (стадия I-ІІА и нет неблагоприятных факторов):}

- Проводится 2 курса ABVD.

- Выполняется ПЭТ-КТ.

- При достижении ПЭТ(-) ПР проводится наблюдение.

- При достижении ПЭТ(+) ЧО проводится радиотерапия $20 \mathrm{~Gy}$ и последующее наблюдение.

- При ПЭТ(+) статусе менее ЧО проводится 4 курса BEACOPР-14 или BEACOPPesc (на усмотрение лечебного учреждения) с промежуточной КТ после 2-х курсов. При наличии прогрессии по данным промежуточной КТ, пациент переводится на вторую линию терапии, во все остальных случаях продолжается терапия ВЕАСОРР-14 или BEACOPPesc.

- При ПЭТ(-) ПР после 4 курсов ВЕАСОРР-14 или BEACOРРеsс проводится наблюдение.

- При ПЭТ(+) статусе, размере лимфоузлов менее 2.5 см и $\mathrm{SUV}<6$ после 4 курсов BEACOPР-14 или BEACOPPesc проводится радиотерапия $30 \mathrm{~Gy}$, при размере лимфоузлов более 2.5 см или SUV>6 пациент переводится на вторую линию терапии.

\section{Интенсивная ветка протокола (стадия IIB-IV или есть неблагоприятные факторы):}

- Проводится 2 курса BEACOPР-14 или BEACOPPesc (на усмотрение лечебного учреждения).

• Выполняется ПЭТ-КТ.

- При достижении ПЭТ(-) ПР проводится рандомизация со стратификацией риска по международной прогностической системе (IPS) между 4 курсами ABVD и AVD. После 2-х курсов выполняется промежуточная KT. При сохранении ремиссии проводится еще два курca, при наличии рецидива пациент переводится на 2-ую линию. После завершения терапии проводится ПЭТ-КТ, при сохранении ремиссии проводится наблюдение.

- При наличии ПЭТ(+) статуса, но без критериев прогрессии, проводится 4 курса ВЕАСОРР-14 или BEACOPPesc (на усмотрение лечебного учреждения) с промежуточной КТ после 2-х курсов. При наличии прогрессии по данным промежуточной КТ, пациент переводится на вторую линию терапии, во все остальных случаях продолжается терапия BEACОРР-14 или BEACOPPesc.
- При ПЭТ(+) статусе, размере лимфоузлов менее 2.5 см и SUV<6 после 6 курсов BEACOPP-14 или BEACOPPesc проводится радиотерапия $30 \mathrm{~Gy}$, при размере лимфоузлов более 2.5 см или SUV>6 пациент переводится на вторую линию терапии.

- При наличии прогрессии на любом этапе, пациент переводится на вторую линию терапии.

\section{Вторая линия химиотерапии:}

- Курсы химиотерапии ICE, IGEV, DHAP, бендамустин + брентуксимаб 2 курса (на усмотрение лечебного учреждения) для следующих групп пациентов с:

- IPS 1-3;

- Химиочувствительная опухоль (по крайней мере, ЧО на 1-ой линии химиотерапии).

- Терапия брентуксимаб \pm бендамустин 2 курса для пациентов с:

- IPS 4;

- Химиорезистентная опухоль (менее ЧО на 1-ой линии химиотерапии).

- Терапия брентуксимаб \pm бендамустин 2 курса также доступна по желанию пациента и при наличии возможности учреждения проводить данный вид терапии.

- При наличии прогрессии на любом этапе лечения или отсутствия ЧО пациент переводится на вторую линию терапии.

\section{Аутологичная трансплантация}

Аутологичная трансплантация выполняется всем пациентам, получивших по крайней мере частичный ответ на 2-ой линии химиотерапии. Режим мобилизации стволовых клеток и режим кондиционирования оставляется на усмотрение трансплантационного центра.

\section{Поддержка брентуксимабом после аутологичной ТГСК}

Поддержка не рекомендована для следующих пациентов при наличии всех факторов (благоприятный прогноз):

- рецидив позднее 1 года от диагноза;

- нет экстранодального поражения в рецидиве;

- полный ответ после 2-ой линии химиотерапии;

- нет bulky опухоли в рецидиве.

Поддержка может проводиться (на усмотрение лечащего учреждения) для пациентов, имеющих хотя бы 1 из факторов (неблагоприятный прогноз):

- рецидив ранее 1 года от диагноза или отсутствие полной ремиссии после 1-ой линии;

- есть экстранодальное поражение в рецидиве;

- менее, чем полный ответ после 2-ой линии химиотерапии;

- есть bulky опухоль в рецидиве. 


\section{Третья линия химиотерапии:}

- Для всех пациентов рекомендована терапия брентуксимаб \pm бендамустин 2 курса.

- При наличии ЧО или ПО после 2-х курсов пациент направляется на аллогенную ТГСК или лучшую доступную терапию при невозможности проведения аллоТГСК.

\section{Ветка протокола для ВИЧ-ассоциированной лимфомы Ходжкина (рисунок 2):}

\section{Рисунок 2. Лечение пациентов с ВИЧ инфекцией}

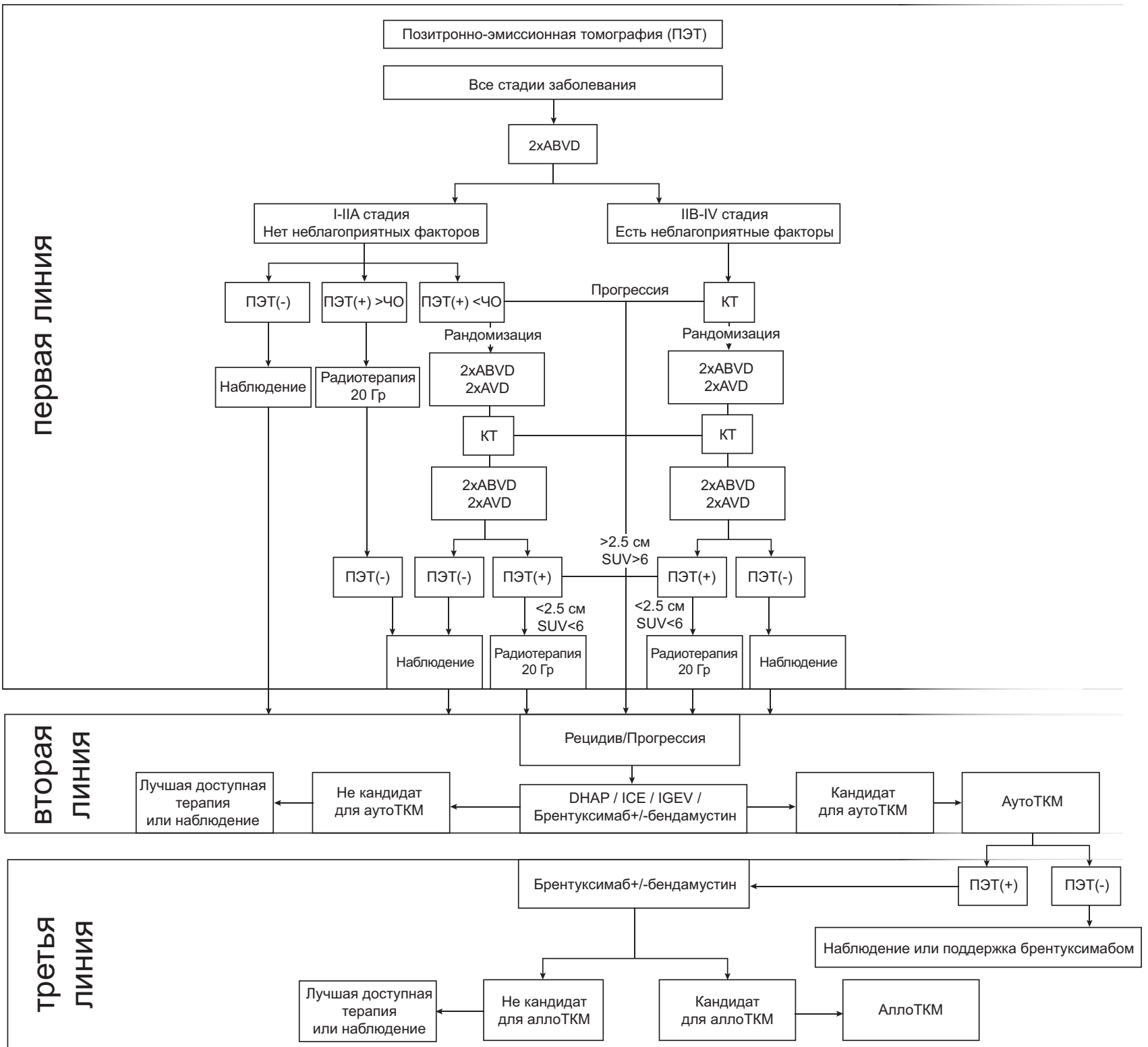

Химиотерапия проводится только на фоне высокоактивной антиретровирусной терапии (HAART), совместно с инфекционистом. Инфекционист может внести коррекцию в антиретровирусную терапию, в зависимости от сочетаемости препаратов с химиопрепаратами.

- Для всех стадий заболевания (I-IV) проводится 2 курса ABVD.

• Выполняется ПЭТ-КТ.
- При достижении ПЭТ(-) ПР для стадий I-IIA без неблагоприятных факторов проводится наблюдение.

- При достижении ПЭТ(-) ПР или ПЭТ(+) ЧО для стадий IIB-IV или при наличии неблагоприятных факторов проводится рандомизация со стратификацией риска по IPS между 4 курсами ABVD и AVD с промежуточной KT после двух курсов. 
- При достижении ПЭТ(+) ЧО для стадий I-IIA проводится радиотерапия $30 \mathrm{~Gy}$ и последующее наблюдение.

- При ПЭТ(+) статусе для стадий IIB-IV, размере лимфоузлов менее 2.5 см и SUV<6 после 4 курсов ABVD или $\mathrm{AVD}$ проводится радиотерапия $30 \mathrm{~Gy}$, при размере лимфоузлов более 2.5 см или SUV>6 пациент переводится на вторую линию терапии.

- При наличии прогрессии на любом этапе лечения пациент переводится на вторую линию терапии.

\section{Вторая линия химиотерапии:}

- Курсы химиотерапии ICE, IGEV, DHAP 2 курса (на усмотрение лечебного учреждения) для следующих групп пациентов с:

- IPS 1-3;

- Химиочувствительная опухоль (по крайней мере, ЧО на 1-ой линии химиотерапии).

- Терапия брентуксимаб \pm бендамустин 2 курса для пациентов с:

- IPS 4;

- Химиорезистентная опухоль (менее ЧО на 1-ой линии химиотерапии).

- Терапия брентуксимаб \pm бендамустин 2 курса также доступна по желанию пациента и при наличии возможности учреждения проводить данный вид терапии.

- При наличии прогрессии на любом этапе лечения или отсутствия ЧО пациент переводится на вторую линию терапии.

\section{Аутологичная трансплантация}

Аутологичная трансплантация выполняется всем пациентам, получивших по крайней мере частичный ответ на 2-ой линии химиотерапии. Режим мобилизации стволовых клеток и режим кондиционирования оставляется на усмотрение трансплантационного центра.

\section{Поддержка брентуксимабом после аутологичной ТГСК:}

Поддержка не рекомендована для следующих пациентов при наличии всех факторов (благоприятный прогноз):

- рецидив позднее 1 года от диагноза;

- нет экстранодального поражения в рецидиве;

- полный ответ после 2-ой линии химиотерапии;

- нет bulky опухоли в рецидиве.

Поддержка может проводиться (на усмотрение лечащего учреждения) для пациентов, имеющих хотя бы 1 из факторов (неблагоприятный прогноз):

- рецидив ранее 1 года от диагноза или отсутствие полной ремиссии после 1-ой линии;

- есть экстранодальное поражение в рецидиве;

- менее, чем полный ответ после 2-ой линии химиотерапии;

- есть bulky опухоль в рецидиве.

\section{Третья линия химиотерапии:}

- Для всех пациентов рекомендована терапия брентуксимаб \pm бендамустин 2 курса.

- При наличии ЧО или ПО после 2-х курсов пациент направляется на аллогенную ТГСК или лучшую доступную терапию при невозможности проведения аллоТГСК.

\section{3. ПРИЛОЖЕНИЕ 2. СХемЫ}

\section{химиотерапии и критерии}

\section{изменения сроков введения и доз препаратов}

\section{Схемы химиотерапии.}

\section{Курс полихимиотерапии ABVD:}

- A: доксорубицин: доза 25 мг/м2 вводится в/в струйно в дни 1 и 15 каждого 28-дневного цикла;

- В: блеомицин: доза 10 мг/м2 вводится в/в 15-минутной инфузией в дни 1 и 15 каждого 28-дневного цикла;

- V: винбластин: доза 6 мг/м2 вводится в/в струйно в дни 1 и 15 каждого 28-дневного цикла;

- D: дакарбазин: доза 375 мг/м2 вводится в/в 60-минутной инфузией в дни 1 и 15 каждого 28-дневного цикла.

\section{Курс полихимиотерапии AVD:}

- А: доксорубицин: доза 25 мг/м2 вводится в/в струйно в дни 1 и 15 каждого 28-дневного цикла;

- V: винбластин: доза 6 мг/м2 вводится в/в струйно в дни 1 и 15 каждого 28-дневного цикла;

- D: дакарбазин: доза 375 мг/м2 вводится в/в 30-минутной инфузией в дни 1 и 15 каждого 28-дневного цикла.

\section{Курс полихимиотерапии ВЕАСОРР-14:}

- В: блеомицин: доза 10 мг/м2 вводится в/в 15-минутной инфузией на 8 день каждого 14-дневного цикла;

- Е: этопозид: доза 100 мг/м2 вводится в/в 1-часовой инфузией в дни 1, 2 и 3 каждого 14-дневного цикла;

- А: доксорубицин: доза 25 мг/м2 вводится в/в струйно в день 1 каждого 14-дневного цикла;

- С: циклофосфамид: доза 650 мг/м2 вводится в/в струйно в день 1 каждого 14-дневного цикла;

- О: винкристин: доза 1.4 мг/м2 (максимально 2 мг) вводится в/в струйно на 8 день каждого 14-дневного цикла; - Р: прокарбазин: доза 100 мг/м2 (округлить до 50 мг) принимается перорально в дни 1-7 каждого 14-дневного цикла;

- Р: преднизолон: доза 40 мг/м2 принимается перорально в дни 1-8 каждого 14-дневного цикла;

- Филграстим 5 мкг/кг вводится п/к в дни 8-13 каждого 14-дневного цикла, введение пропускается при уровне лейкоцитов более 15 тыс. в мкл. 
Курс полихимиотерапии BEACOPP escalated:

• В: блеомицин: доза 10 мг/м2 вводится в/в 15-минутной инфузией на 8 день каждого 21-дневного цикла;

- Е: этопозид: доза 200 мг/м2 вводится в/в 1-часовой инфузией в дни 1, 2 и 3 каждого 21-дневного цикла;

- А: доксорубицин: доза 35 мг/м2 вводится в/в струйно в день 1 каждого 21-дневного цикла;

- С: циклофосфамид: доза 1250 мг/м2 вводится в/в струйно в день 1 каждого 21-дневного цикла;

- О: винкристин: доза 1.4 мг/м2 (максимально 2 мг) вводится в/в струйно на 8 день каждого 21-дневного цикла;

- P: прокарбазин: доза 100 мг/м2 (округлить до 50 мг) принимается перорально в дни 1-7 каждого 21-дневного цикла;

- Р: преднизолон: доза 40 мг/м2 принимается перорально в дни 1-14 каждого 21-дневного цикла;

- Филграстим 5 мкг/кг вводится п/к с дня 8 ЛИБО при снижении нейтрофилов менее 1000/мкл (на усмотрение лечебного учреждения) до восстановления нейтрофилов выше 1000/мкл в течение 3 последовательных дней, введение пропускается при уровне лейкоцитов более 15 тыс. в мкл.

\section{Курс полихимиотерапии ВЕАСОРP-14 с дакарбазином:}

- Используется только при отсутсвии доступа к прокарбазину;

- B: блеомицин: доза 10 мг/м2 вводится в/в 15-минутной инфузией на 8 день каждого 14-дневного цикла;

- Е: этопозид: доза 100 мг/м2 вводится в/в 1-часовой инфузией в дни 1, 2 и 3 каждого 14-дневного цикла;

- А: доксорубицин: доза 25 мг/м2 вводится в/в струйно в день 1 каждого 14-дневного цикла;

- С: циклофосфамид: доза 650 мг/м2 вводится в/в струйно в день 1 каждого 14-дневного цикла;

- О: винкристин: доза 1.4 мг/м2 (максимально 2 мг) вводится в/в струйно на 8 день каждого 14-дневного цикла;

- Р: дакарбазин: доза 375 мг/м2 в/в 1-часовой инфузией в день 1 каждого 14-дневного цикла;

- Р: преднизолон: доза 40 мг/м2 принимается перорально в дни 1-8 каждого 14-дневного цикла;

- Филграстим 5 мкг/кг вводится п/к в дни 8-13 каждого 14-дневного цикла, введение пропускается при уровне лейкоцитов более 15 тыс. в мкл.

\section{Курс полихимиотерапии BEACOPP escalated c дакарбазином:}

- Используется только при отсутсвии доступа к прокарбазину;

- В: блеомицин: доза 10 мг/м2 вводится в/в 15-минутной инфузией на 8 день каждого 21-дневного цикла;

- Е: этопозид: доза 200 мг/м2 вводится в/в 1-часовой инфузией в дни 1, 2 и 3 каждого 21-дневного цикла;

- А: доксорубицин: доза 35 мг/м2 вводится в/в струйно в день 1 каждого 21-дневного цикла;
- С: циклофосфамид: доза 1250 мг/м2 вводится в/в струйно в день 1 каждого 21-дневного цикла;

- О: винкристин: доза 1.4 мг/м2 (максимально 2 мг) вводится в/в струйно на 8 день каждого 21-дневного цикла; - P: дакарбазин: доза 375 мг/м2 в/в 1-часовой инфузией в день 1 каждого 14-дневного цикла;

- P: преднизолон: доза 40 мг/м2 принимается перорально в дни 1-14 каждого 21-дневного цикла;

- Филграстим 5 мкг/кг вводится п/к с дня 8 ЛИБО при снижении нейтрофилов менее 1000/мкл (на усмотрение лечебного учреждения) до восстановления нейтрофилов выше 1000/мкл в течение 3 последовательных дней, введение пропускается при уровне лейкоцитов более 15 тыс. в мкл.

\section{Курс полихимиотерапии DHAP:}

- D: дексаметазон: доза 40 мг вводится в/в 30-минутной инфузией или перорально в дни 1-4 каждого 28-дневного цикла;

- НА: цитозар: доза 2000 мг/м2 два раза в день вводится в/в 2-часовой инфузией после окончания введения цисплатина каждого 28-дневного цикла;

- P: цисплатин: доза 100 мг/м2 вводится в/в 24-часовой инфузией в день 1 каждого 28-дневного цикла;

Допустимо начало следующего цикла ранее 28 дня в случае восстановления показателей периферической крови.

\section{Курс полихимиотерапии ICE:}

- I: ифосфамид: доза 5 г/м2 вводится в/в 24-часовой инфузией в день 2 каждого 28-дневного цикла;

- C: карбоплатин: доза 400 мг/м2 вводится в/в 2-часовой инфузией в день 2 каждого 28-дневного цикла;

- Е: этопозид: доза 100 мг/м2 вводится в/в 1-часовой инфузией в дни 1-3 каждого 28-дневного цикла;

Допустимо начало следующего цикла ранее 28 дня в случае восстановления показателей периферической крови.

\section{Курс полихимиотерапии IGEV:}

- I: ифосфамид: доза 2 г/м2 вводится в/в 2-часовой инфузией в дни 1-4 каждого 21-дневного цикла;

- GE: гемцитабин: доза 800 мг/м2 вводится в/в 2-часовой инфузией в дни 1-4 каждого 21-дневного цикла;

- V: винорельбин: доза 20 г/м2 вводится в/в 30-минутной инфузией в день 1 каждого 21-дневного цикла;

- преднизолон: доза 100 мг вводится в/в 30-минутной инфузией или перорально в дни 1-4 каждого 21-дневного цикла.

\section{Брентуксимаб:}

- доза 1.8 мг/кг вводится в/в 30-минутной инфузией в день 1 каждого 21-дневного цикла.

\section{Брентуксимаб+бендамустин:}

- брентуксимаб: доза 1.8 мг/кг вводится в/в 30-минутной инфузией в день 1 каждого 21-дневного цикла; - бендамустин: доза 90 мг/м2 вводится в/в 1-часовой инфузией в день 1 и 2 каждого 21-дневного цикла. 


\section{Редукция доз химиопрепаратов при почечной недостаточности:}

Расчет клиренса креатинина будет проводится автоматически при первичной регистрации пациента и перед началом второй линии терапии по формуле Кокрофта-Гаута.

- блеомицин: клиренс креатинина 10-50 мл/мин - 75\% дозы, клиренс креатинина $<10$ мл/мин - 50\% дозы;

• доксорубицин: коррекция дозы не проводится;

- винбластин/винкристин: коррекция дозы не проводится;

- дакарбазин: клиренс креатинина 45-60 мл/мин - 80\% дозы, клиренс креатинина 30-45 мл/мин - 75\% дозы, клиренс креатинина <30 мл/мин - 70\% дозы;

- прокарбазин: клиренс креатинина <50 мл/мин - 50\% дозы;

- циклофосфамид: клиренс креатинина 10-20 мл/мин 75\% дозы;

- этопозид: клиренс креатинина 15-50 мл/мин - 75\% дозы, клиренс креатинина <15 мл/мин - 50\% дозы;

- цитарабин: клиренс креатинина 45-60 мл/мин - 60\% дозы, клиренс креатинина 30-45 мл/мин - 50\% дозы, клиренс креатинина $<45$ мл/мин - выбор альтернативной схемы;

- карбоплатин: клиренс креатинина 20-40 мл/мин - доза 250 мг/м2, клиренс креатинина $<20$ мл/мин - выбор альтернативной схемы;

- цисплатин: клиренс креатинина 45-60 мл/мин - 75\% дозы, клиренс креатинина <45мл/мин - выбор альтернативной схемы;

- ифосфамид: клиренс креатинина 45-60 мл/мин - 70\% дозы, клиренс креатинина $<45$ мл/мин - выбор альтернативной схемы;

- гемцитабин: клиренс креатинина $<30$ мл/мин - нет редукции или 75\% дозы;

- винорельбин: коррекция дозы не проводится;

• бендамутин: коррекция дозы не проводится.

\section{Сопроводительная терапия:}

ABVD/AVD:

- Внутривенная или пероральная гидратация не менее 1 литра в дни введения химиопрепаратов;

- Ондасетрон 8 мг в дни введения химиопрепаратов;

- Аллопуринол 300-600 мг (на усмотрение лечащего врача) в дни 1-7, 15,21 каждого цикла;

- Антибактериальная профилактика ципрофлоксацином 500 мг 2 p\д ПО назначается только при наличии агранулоцитоза более 3 дней или фебрильной нейтропении на предыдущем курсе химиотерапии;

- Профилактика пневмоцистной пневмонии триметопримом/сульфаметоксазолом 960 мг 2 р\д 3 раза в неделю назначается только ВИЧ-инфецированным пациентам.

\section{BEACOPP14/BEACOPPesc:}

- Внутривенная или пероральная гидратация не менее 1.5 литра/м2 в дни введения химиопрепаратов;

- Ондасетрон 8 мг 2 раза в день в дни введения химиопрепаратов, допускается усиление дексаметазоном 4 мг или апрепитантом 80-125 мг;

- Омепразол 20-40 мг 2 раза в день весь период лечения;

- Ципрофлоксацин 500 мг 2 раза в день весь период лечения (если не противоречит стандартам противоинфекционной профилактики учреждения);

- Триметопримом/сульфаметоксазолом 960 мг 2 р \д 3 раза в неделю весь период лечения

- Аллопуринол 300-600 мг (на усмотрение лечащего врача) в дни 1-7 каждого цикла;

- Для женщин - регивидон 1 т/сутки или босерелин/госерелин депо (на усмотрение лечащего врача) весь период лечения.

DHAP:

- Внутривенная гидратация не менее 3 литров/м2 в дни введения химиопрепаратов $(50 \%-0.9 \% \mathrm{NaCl}, 50 \%-5 \%$ глюкоза);

- Введение не менее 40 мл 10\% $\mathrm{KCl}$ в день продленной инфузией или дробно в рамках гидратации

- Маннитол 20\% 40 мл/м2 за 3 часа и 30 минут до введения цисплатина. Маннитол 20\% 100 мл при снижении диуреза менее чем 400 мл/м2/6 часов. Назначение петлевых диуретиков в период во время введения цисплатина запрещено.

- Ондасетрон 8 мг 2 раза в день в дни введения химиопрепаратов, допускается усиление дексаметазоном 4 мг или апрепитантом 80-125 мг;

- Омепразол 20-40 мг 2 раза в день весь период лечения; - Ципрофлоксацин 500 мг 2 раза в день весь период лечения (если не противоречит стандартам противоинфекционной профилактики учреждения);

- Триметопримом/сульфаметоксазолом 960 мг 2 р\д 3 раза в неделю весь период лечения

- Аллопуринол 300-600 мг (на усмотрение лечащего врача) в дни 1-7 каждого цикла;

- Для женщин - регивидон 1 т/сутки или босерелин/госерелин депо (на усмотрение лечащего врача) весь период лечения.

ICE:

- Внутривенная гидратация не менее 3 литров/м2 в дни введения химиопрепаратов (50\% - 0.9\% NaCl, 50\% - 5\% глюкоза);

- Введение не менее 40 мл 10\% $\mathrm{KCl}$ в день продленной инфузией или дробно в рамках гидратации

- уромитексан 5 г/м2 24-частовая инфузия одновременно с ифосфамидом

- Ондасетрон 8 мг 2 раза в день в дни введения химиопрепаратов, допускается усиление дексаметазоном 4 мг или апрепитантом 80-125 мг; 
- Омепразол 20-40 мг 2 раза в день весь период лечения;

- Ципрофлоксацин 500 мг 2 раза в день весь период лечения (если не противоречит стандартам противоинфекционной профилактики учреждения);

- Триметопримом/сульфаметоксазолом 960 мг 2 p \д 3 раза в неделю весь период лечения

- Аллопуринол 300-600 мг (на усмотрение лечащего врача) в дни 1-7 каждого цикла;

- Для женщин - регивидон 1 т/сутки или босерелин/госерелин депо (на усмотрение лечащего врача) весь период лечения.

\section{IGEV:}

- Внутривенная гидратация не менее 1.5 литров/м2 в дни введения химиопрепаратов (50\% - 0.9\% NaCl, $50 \%$ $5 \%$ глюкоза);

- Введение не менее 40 мл 10\% $\mathrm{KCl}$ в день продленной инфузией или дробно в рамках гидратации;

- Уромитексан 5 г/м2 24-частовая инфузия одновременно с ифосфамидом;

- Ондасетрон 8 мг 2 раза в день в дни введения химиопрепаратов, допускается усиление дексаметазоном 4 мг или апрепитантом 80-125 мг;

- Омепразол 20-40 мг 2 раза в день весь период лечения;

- Ципрофлоксацин 500 мг 2 раза в день весь период лечения (если не противоречит стандартам противоинфекционной профилактики учреждения);

- Триметопримом/сульфаметоксазолом 960 мг 2 р \д 3 раза в неделю весь период лечения;

- Аллопуринол 300-600 мг (на усмотрение лечащего врача) в дни 1-7 каждого цикла;

- Для женщин - регивидон 1 т/сутки или босерелин/госерелин депо (на усмотрение лечащего врача) весь период лечения.

\section{Брентуксимаб+бендамустин:}

- Внутривенная или пероральная гидратация не менее 1.0 литра/м2 в дни введения бендамустина;

- Ондасетрон 8 мг в дни введения химиопрепаратов, допускается усиление дексаметазоном 4 мг или апрепитантом 80-125 мг;

- Омепразол 20-40 мг 2 раза в день весь период лечения;

- Триметопримом/сульфаметоксазолом 960 мг 2 р \д 3 раза в неделю весь период лечения

- Аллопуринол 300-600 мг (на усмотрение лечащего врача) в дни 1-7 каждого цикла;

- Для женщин - регивидон 1 т/сутки или босерелин/госерелин депо (на усмотрение лечащего врача) весь период лечения.

\section{Условия коррекции сроков начала следующего курса:}

Начало следующего курса может быть отложено в случае:

- Уровня нейтрофилов менее 1000/мкл на момент наличия цикла (если не связано с доказанным поражением костного мозга);
- Уровня тромбоцитов менее 50000 /мкл на момент наличия цикла (если не связано с доказанным поражением костного мозга);

- Наличие тяжелой бактериальной или грибковой инфекции с сохраняющейся системной воспалительной реакцией (фебрильная лихорадка, С-реактивный белок $>70$ мг/л) или органной недостаточностью (дыхательная, сердечно-сосудистая, почечная или печеночная) на момент начала цикла;

- Уровень гемоглобина НЕ является основанием для переноса сроков начала следующего цикла, показана трансфузия эритроцитарных компонентов при наличии тяжелого анемического синдрома.

\section{4. СПИСОК ЛИТЕРАТУРЫ}

1. Bonadonna G, Zucali R, Monfardini S et al. Combination chemotherapy of Hodgkin's disease with adriamycin, bleomycin, vinblastine, and imidazole carboxamide versus MOPP. Cancer. 1975;36(1):252-259.

2. Cheson BD. Which Hodgkin's patients in the Unites States should be treated with BEACOPP? Curr Hematol Malig Rep. 2014 Sep;9(3):222-226.

3. Diehl V, Franklin J, Pfreundschuh $\mathrm{M}$ et al. Standard and increased-dose BEACOPP chemotherapy compared with COPP-ABVD for advanced Hodgkin's disease. N Engl J Med. 2003;348(24):2386-2395.

4. Eich HT, Diehl V, Görgen H et al. Intensified chemotherapy and dose-reduced involved-field radiotherapy in patients with early unfavorable Hodgkin's lymphoma: final analysis of the German Hodgkin Study Group HD11 trial. J Clin Oncol. 2010;28(27):4199-4206.

5. Sieniawski M, Reineke T, Josting A et al. Assessment of male fertility in patients with Hodgkin's lymphoma treated in the German Hodgkin Study Group (GHSG) clinical trials. Ann Oncol. 2008;19(10):1795-1801.

6. Merli F, Luminari S, Gobbi PG et al. Long-Term Results of the HD2000 Trial Comparing ABVD Versus BEACOPP Versus COPP-EBV-CAD in Untreated Patients With Advanced Hodgkin Lymphoma: A Study by Fondazione Italiana Linfomi. J Clin Oncol. 2016;34(11):1175-1181.

7. Engert A, Haverkamp H, Kobe C et al. Reduced-intensity chemotherapy and PET-guided radiotherapy in patients with advanced stage Hodgkin's lymphoma (HD15 trial): a randomised, open-label, phase 3 non-inferiority trial. Lancet. 2012;379(9828):1791-1799.

8. Borchmann P, Haverkamp H, Diehl V et al. Eight cycles of escalated-dose BEACOPP compared with four cycles of escalated-dose BEACOPP followed by four cycles of baseline-dose BEACOPP with or without radiotherapy in patients with advanced-stage hodgkin's lymphoma: final analysis of the HD12 trial of the German Hodgkin Study Group. J Clin Oncol. 2011;29(32):4234-4242.

9. von Tresckow B, Plütschow A, Fuchs M et al. Dose-intensification in early unfavorable Hodgkin's lymphoma: final analysis of the German Hodgkin Study Group HD14 trial. J Clin Oncol. 2012;30(9):907-913. 
10. Engert A, Plütschow A, Eich HT et al. Reduced treatment intensity in patients with early-stage Hodgkin's lymphoma. N Engl J Med. 2010;363(7):640-652.

11. Meyer RM, Gospodarowicz MK, Connors JM et al. ABVD alone versus radiation-based therapy in limited-stage Hodgkin's lymphoma. N Engl J Med. 2012; 366(5):399-408.

12. Eichenauer DA, Engert A. 2012; Advances in the treatment of Hodgkin lymphoma. Int J Hematol 96:535-543.

13. Johnson P, Federico M, Kirkwood A et al. Adapted Treatment Guided by Interim PET-CT Scan in Advanced Hodgkin’s Lymphoma. N Engl J Med. 2016;374(25):2419-2429.

14. Engert A. ABVD or BEACOPP for Advanced Hodgkin Lymphoma. J Clin Oncol. 2016;34(11):1167-1169.

15. Uldrick TS, Little RF et al. How I treat classical Hodgkin lymphoma in patients infected with human immunodeficiency virus. Blood. 2015;125(8):1226-1235.

16. Press OW, Li H, Schöder $\mathrm{H}$ et al. US Intergroup Trial of Response-Adapted Therapy for Stage III to IV Hodgkin Lymphoma Using Early Interim Fluorodeoxyglucose-Positron Emission Tomography Imaging: Southwest Oncology Group S0816. J Clin Oncol. 2016;34(17):2020-2027.

17. Andreas Engert,Sandra J. Horning. 2011; Hodgkin Lymphoma: A Comprehensive Update on Diagnostics and Clinics. Springer-Verlag, Berlin.

18. Zinzani PL, Vitolo U, Viviani S et al. Safety and efficacy of single-agent bendamustine after failure of brentuximab vedotin in patients with relapsed or refractory hodgkin's lymphoma: experience with 27 patients. Clin Lymphoma Myeloma Leuk. 2015;15(7):404-408.
19. Younes A, Gopal AK, Smith SE et al. Results of a pivotal phase II study of brentuximab vedotin for patients with relapsed or refractory Hodgkin's lymphoma. J Clin Oncol. 2012;30(18):2183-2189.

20. Moskowitz CH, Nimer SD, Glassman JR et al. The International Prognostic Index predicts for outcome following autologous stem cell transplantation in patients with relapsed and primary refractory intermediate-grade lymphoma. Bone Marrow Transplant. 1999;23(6):561-567.

21. Satwani P, Ahn KW, Carreras J et al. A prognostic model predicting autologous transplantation outcomes in children, adolescents and young adults with Hodgkin lymphoma. Bone Marrow Transplant. 2015;50(11):1416-1423.

22. Moskowitz CH, Nademanee A, Masszi T et al. Brentuximab vedotin as consolidation therapy after autologous stemcell transplantation in patients with Hodgkin's lymphoma at risk of relapse or progression (AETHERA): a randomised, double-blind, placebo-controlled, phase 3 trial. Lancet. 2015;385(9980):1853-1862.

23. Cheson BD, Pfistner B, Juweid ME, Gascoyne RD, Specht L, Horning SJ, et al. Revised response criteria for malignant lymphoma. Journal of Clinical Oncology 2007;25(5):579586.

24. Аль-Ради Л.С., Барях Е.А, Белоусова И.Э. и др. Клинические рекомендации по диагностике и лечению лимфопролиферативных заболеваний. Москва, 2014. Опубликовано: oncology-association.ru/docs/ recomend/2016/59klin-rek.pdf. 